Original Research Article

\title{
Traffic accidents and medicine use in United Arab Emirates
}

\author{
Suleiman I. Sharif*, Manal Al Sharawy, Dalia Makrem, Esraa Qasim, Dania Shemi
}

Department of Pharmacy,

Practice and

Pharmacotherapeutics, College

of Pharmacy, University of

Sharjah, Sharjah, United Arab

Emirates

Received: 17 January 2018

Accepted: 28 February 2018

*Correspondence to:

Dr. Suleiman I. Sharif,

Email: sharifsi@sharjah.ac

Copyright: (C) the author(s), publisher and licensee Medip Academy. This is an openaccess article distributed under the terms of the Creative Commons Attribution NonCommercial License, which permits unrestricted noncommercial use, distribution, and reproduction in any medium, provided the original work is properly cited.

\begin{abstract}
Background: The present study was undertaken to evaluate the knowledge, attitude and practice of drivers of the cautious driving while taken prescription and OTC drugs.

Methods: A cross sectional questionnaire was developed, pre-validated and distributed to 150 drivers who showed willingness to participate in the study. The survey included questions on driving habits, number of accidents, and number of accidents due to sleep or medication use.

Results: All drivers approached answered the questionnaire producing a $100 \%$ response rate with male: female ration being 1.2: 1 . Slightly more than half $(78$, 52 and $80,53.3 \%$ ) the responders were within 17-28 years of age and with a university degree respectively. More than $50 \%$ of respondents follow driving regulations and more than two thirds $(112,74.4 \%)$ use seat built again the majority $(133,88.7 \%)$ never had traffic accidents. Use of medications as a cause of accidents was reported by only $4(2.7 \%)$ drivers.

Conclusions: Regardless of the low incidence of medication use related accidents, authorities are advised to develop new regulations with respect to driving under the influence of medications or when suffering diseases that affect driving ability.
\end{abstract}

Keywords: Medication use, Sleep, Traffic regulations, Traffic accidents

\section{INTRODUCTION}

Traffic accidents and injuries are serious problems that need increasing concern and are now the most frequent cause of fatalities and admission to hospital. Globally, traffic accidents account for about 480,000 deaths and 20 million injuries by drivers under the influence of alcohol every year. ${ }^{1}$ Concern on the influence of illicit, prescription and Over the Counter (OTC) drugs on judgment of drivers is on the rise and so traffic accidents. In Europe, it has been reported that the prevalence of illicit drug use is in the range $1-5 \%$ whereas that of licit drugs is in the range $5-15 \% .^{2}$ In low- and middle-income countries the rate of death is higher than in Europe as more than $90 \%$ of deaths due to road traffic accidents. ${ }^{3,4}$
It is predicted that if such a trend continues, in the next five years road traffic accidents will result in the death of 6 million people and the injury of 60 million individuals only in developing countries. Road crashes cost globally account for $\$ 518$ billion while in low and middle-income countries $\$ 65$ billion annually, exceeding the total amount received in developmental assistance. ${ }^{5}$ Drivers' fatigue, exhaustion, use of drowsiness and sleep-inducing drugs reduce drivers vigilance and contribute to the most dangerous types of traffic accidents. In addition to illicit drugs, prescription and some OTC drugs contain active constituents that may affect cognition, driver's judgement, and slow his/her reaction. Such problems are further enhanced by the use of mobile phones to chat or text messages while driving. It is also a fact that driving is also 
distracted by eating, drinking, trying to control children and the ignorance of children safety measures in the car. Moreover, high speed and irresponsible driving are not only hazardous to the driver and his/her passengers but also to other drivers and pedestrians.

Prescription drugs and many OTC medications affect cognition and can lead to drowsiness or a slow reaction time, especially when taken along with other medications. Many OTC medications like cough syrups and cold medications contain antihistamines that can cause drowsiness which would certainly influence decisionsmaking skills such as driving or operating machinery. Prescription drugs that impair driving skills include, among others, opioid analgesics, muscle relaxants, hypnotics and sedatives, antidepressants and antiepileptic drugs. It seems reasonable to recommend that both the prescribing physician and the dispensing pharmacist must stress the danger of such adverse effect that interferes with the daily activities of the patient including driving. The present was undertaken to assess driving habits in relation to traffic accidents and use of medications.

\section{METHODS}

\section{Subjects and data collection}

The inclusion criteria were adults who are active car drivers. A total of 150 drivers from Sharjah and Abu Dhabi-UAE were approached and agreed to participate in the survey.

The nature and purpose of the study was explained to drivers who agreed voluntarily to participate in the study through face-to-face interview. The filled in surveys were collected over the study period of three months (September-November 2017). Participants were assured of confidentiality and written informed consent of participants was obtained.

\section{Development of study design}

The cross-sectional study was conducted based on an anonymous questionnaire that was designed by us in both English and Arabic format. The questionnaire was prepiloted by distributing it to 5 drivers within the targeted group, who were interviewed face-to-face, but they were not included in the study, and all their recommendations and comments were considered in the final version of the questionnaire. The survey was approved by the Ethics Committee of the Medical Campus-University of Sharjah. The survey was designed to include questions covering demographic characteristics of the drivers and their driving experiences, average kilometers driven per year, behavior with regard to driving regulations and usage of seat built, and number of traffic accidents due to sleep and whether such accidents were due to medication use (Tables 1 and 2). Participants were also asked about the overall number of traffic accidents experienced within the preceding year. The last part of the survey includes questions on the number of participants within each age group who were taking medications and whether participants read the instruction leaflets of their medication before using it. The collected data were analyzed and presented as frequency and percentage.

\section{RESULTS}

Table 1: Demographic characteristics of participants (150 participants).

\begin{tabular}{|c|c|c|}
\hline Criteria & $\begin{array}{l}\text { Number } \\
\mathrm{N}=150\end{array}$ & $\begin{array}{l}\text { Percentage } \\
(\%)\end{array}$ \\
\hline \multicolumn{3}{|l|}{ Gender } \\
\hline Males & 70 & 46.7 \\
\hline Females & 80 & 53.3 \\
\hline \multicolumn{3}{|l|}{ Age (Years) } \\
\hline $17-22$ & 48 & 32 \\
\hline $23-28$ & 30 & 20 \\
\hline $29-34$ & 17 & 11 \\
\hline $35-40$ & 17 & 20 \\
\hline $41-46$ & 14 & 9.3 \\
\hline $47-52$ & 16 & 10.7 \\
\hline$>52$ & 8 & 5.3 \\
\hline \multicolumn{3}{|l|}{ Marital Status } \\
\hline Single & 75 & 50 \\
\hline Married & 72 & 48 \\
\hline Divorced & 3 & 2 \\
\hline \multicolumn{3}{|l|}{ Educational Level } \\
\hline Elementary school & 3 & 2 \\
\hline Secondary school & 16 & 10.7 \\
\hline University student & 37 & 24.7 \\
\hline University degree & 80 & 53.3 \\
\hline $\begin{array}{l}\text { Graduate degree (MSc, } \\
\mathrm{PhD})\end{array}$ & 14 & 9.3 \\
\hline \multicolumn{3}{|l|}{ Body weight $(\mathrm{Kg})$} \\
\hline $50-59$ & 29 & 19.3 \\
\hline $60-69$ & 24 & 16 \\
\hline $70-79$ & 32 & 21.3 \\
\hline $80-89$ & 40 & 26.7 \\
\hline $90-99$ & 15 & 10 \\
\hline$>99$ & 10 & 6.7 \\
\hline \multicolumn{3}{|l|}{ Height } \\
\hline $150-154$ & 6 & 4 \\
\hline $155-159$ & 18 & 12 \\
\hline $160-164$ & 24 & 16 \\
\hline $165-169$ & 29 & 19.3 \\
\hline $170-174$ & 32 & 21.3 \\
\hline $175-179$ & 27 & 18 \\
\hline$>180$ & 14 & 9.3 \\
\hline \multicolumn{3}{|l|}{ Cigarette smoking } \\
\hline Yes & 28 & 18.7 \\
\hline No & 122 & 81.3 \\
\hline \multicolumn{3}{|l|}{ Having health problem } \\
\hline Yes & 30 & 20 \\
\hline No & 120 & 80 \\
\hline
\end{tabular}


The response rate of the questionnaire was $100 \%$ as all participants willingly answered and delivered back the filled in questionnaire. As shown in Table 1, both males and females participated in the survey with male: female ratio being 1.2:1.

Table 2: Driving habits and number of accidents due to sleep and medications.

\begin{tabular}{|c|c|c|}
\hline Criteria & $\begin{array}{l}\text { Number } \\
\mathrm{N}=150\end{array}$ & $\begin{array}{l}\text { Percentage } \\
(\%)\end{array}$ \\
\hline \multicolumn{3}{|c|}{ Driving experience (Years) } \\
\hline $1-4$ & 69 & 46 \\
\hline $5-9$ & 24 & 16 \\
\hline $10-14$ & 15 & 10 \\
\hline $15-19$ & 15 & 10 \\
\hline $20-24$ & 18 & 12 \\
\hline $25-30$ & 9 & 6 \\
\hline \multicolumn{3}{|c|}{ Average driving kilometers/year } \\
\hline $5000-9000$ & 33 & 22 \\
\hline $10000-14000$ & 27 & 18 \\
\hline $15000-19000$ & 25 & 16.7 \\
\hline $20000-25000$ & 42 & 28 \\
\hline $26000-31000$ & 15 & 10 \\
\hline$>31000$ & 8 & 5.3 \\
\hline \multicolumn{3}{|c|}{ How often you follow driving regulations? } \\
\hline Always & 77 & 51.3 \\
\hline Usually & 66 & 44 \\
\hline Rarely & 6 & 4 \\
\hline Never & 1 & 0.7 \\
\hline \multicolumn{3}{|c|}{ How often do you use seat belt? } \\
\hline Always & 112 & 74.7 \\
\hline Usually & 24 & 16 \\
\hline Rarely & 10 & 6.7 \\
\hline Never & 4 & 2.7 \\
\hline \multicolumn{3}{|c|}{ Number of accidents due to sleep } \\
\hline 0 & 133 & 88.7 \\
\hline 1 & 12 & 8 \\
\hline 2 & 1 & 0.7 \\
\hline 3 & 1 & 0.7 \\
\hline 4 & 1 & 0.7 \\
\hline 5 & 2 & 1.3 \\
\hline$>5$ & 0 & 0 \\
\hline \multicolumn{3}{|c|}{ Was the accident due to use of medicines? } \\
\hline Yes & 4 & 2.7 \\
\hline No & 146 & 97.3 \\
\hline
\end{tabular}

The majority $(78,52 \%)$ of respondents were in the age group of $17-28$ years, with a university degree $(80,43.3 \%)$, healthy $(120,80 \%)$ and non-smokers $(122,81.3 \%)$. Only four drivers were above 52 years of age. With regard to body weight, $125(83.3 \%)$ drivers were of lean to athletic physique whereas $25(16.7 \%)$ of participants were obese drivers. Driving experience of the majority $(69,46 \%)$ of participants exceeds 4 years and only slightly less than 5\% and $10 \%$ of participants either never or rarely follow driving regulations and use of seat built respectively. Only about $11 \%$ of participants admitted being involved in a varying number (1-5) of traffic accidents per year due to sleep. Among the latter, only $4(2.7 \%)$ of participants accused medication use to be the reasons (Table 2).

Those participants believed that their accidents were consequence of drug effects on their judgment or control. The pattern of following driving regulation within each age group is shown in Figure 1.

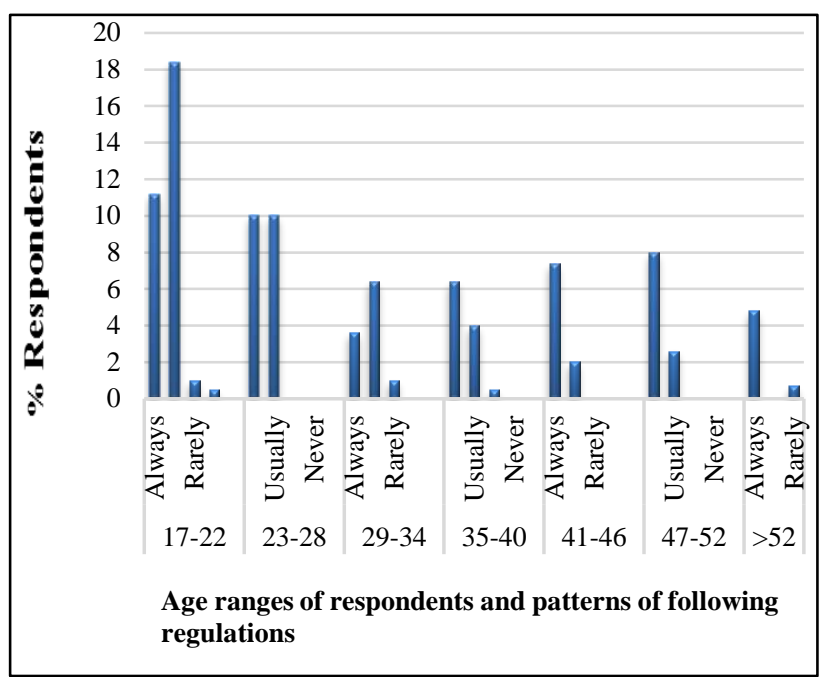

\section{Figure 1: Patterns of following driving regulation within each age range of participants.}

The incidence of intermittent sleeping while driving is illustrated in Figure 2. Clearly participants who experienced this problem comprise about $30 \%$ of all drivers. The overall number of traffic accidents among participants is shown in Figure 3.

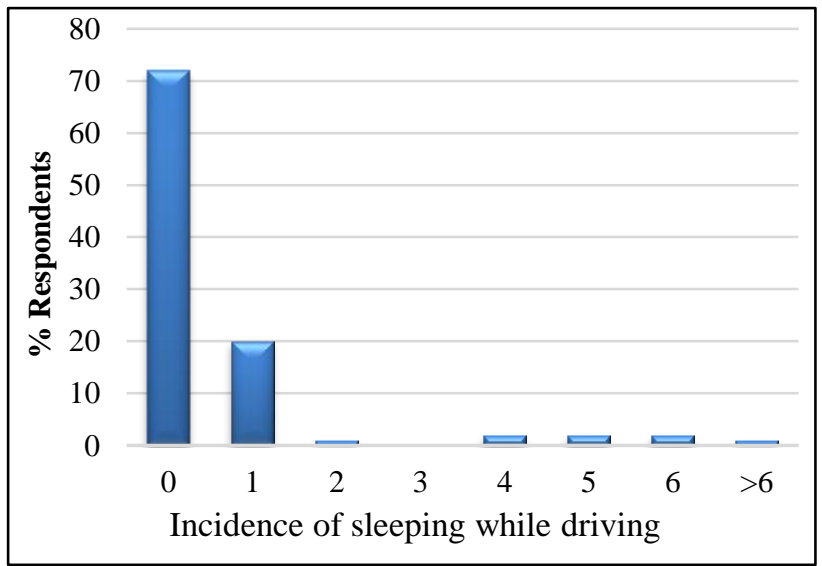

Figure 2: Frequency of falling asleep while driving among participants.

The highest number of accidents is 2 per year but alarmingly about $8 \%$ of participants had more than 5 accidents per year. Percentage of respondents in each age group who are taking medications while driving is shown in Figure 4. 


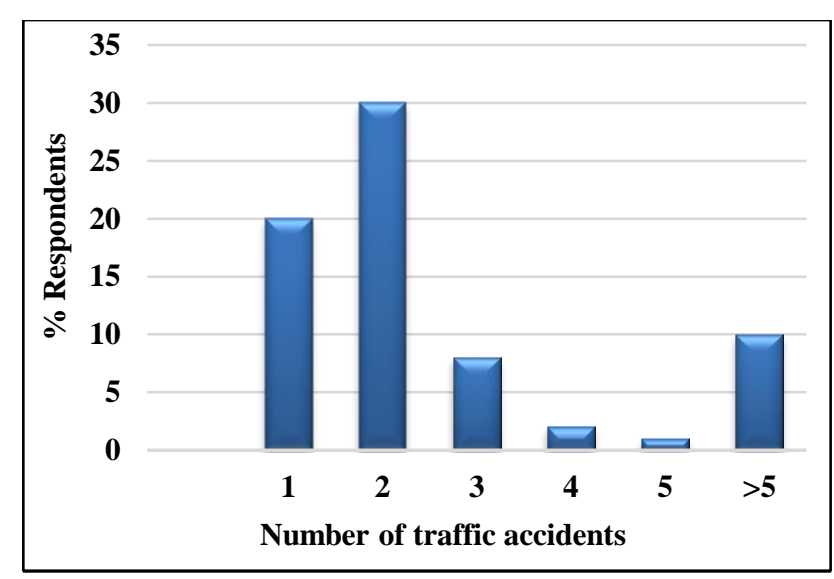

Figure 3: General number of traffic accidents among participants.

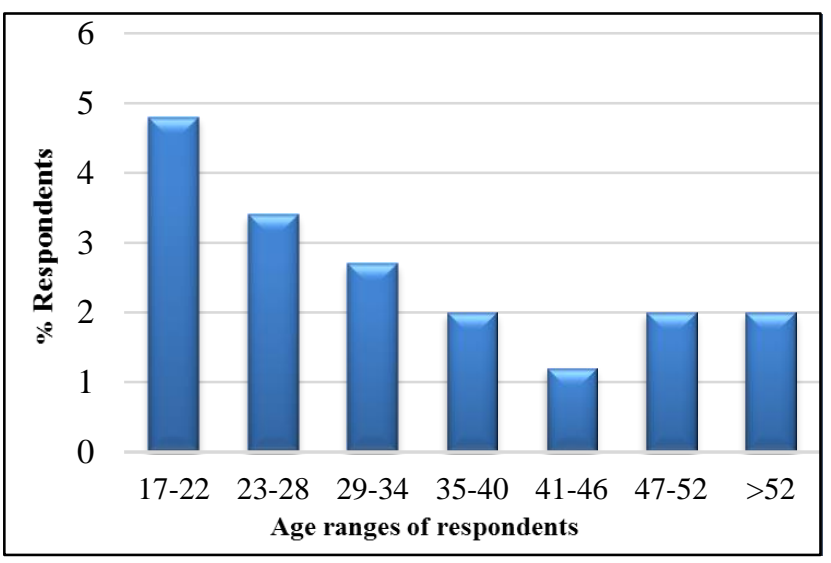

Figure 4: Percentage respondents taking medications within each age group.

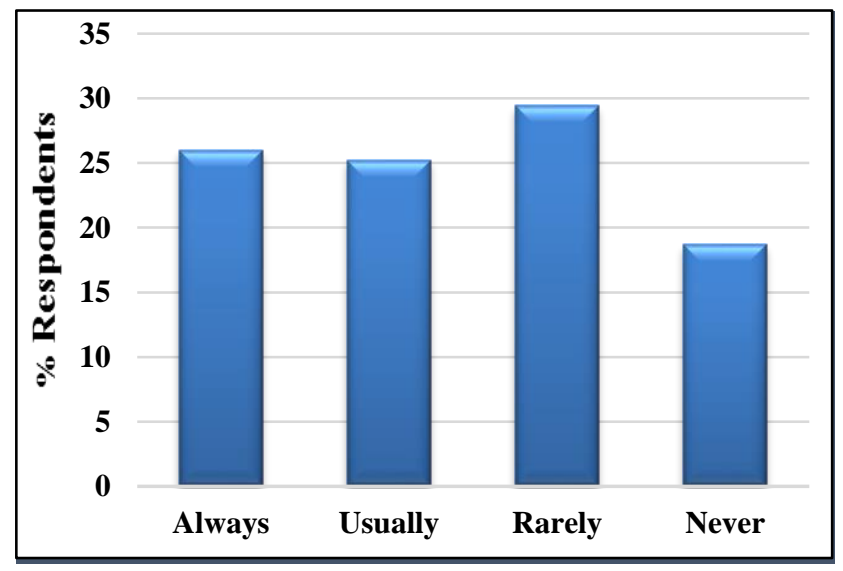

Figure 5: Pattern of reading instruction leaflets of medication before use.

Data on reading information leaflets for purchased medications and warning on use of medicine during driving are shown in Figure 5. As can be seen in these figures, a small number (less 20\%) of drivers were users of medications and a large number of the participants either rarely or never read the leaflet of instructions on the use and warning on use of medication during driving.

\section{DISCUSSION}

Traffic accidents are major concern of all countries and several programs are set by authorities to reduce the rate of such disasters. According to World Health Organization Statistics (WHO), there were 1.25 million road traffic deaths globally in 2013, and higher fatality rates per 100,000 population were recorded for low- and middleincome countries at 24.1 and 18.4 respectively. ${ }^{6}$ It has been pointed out that these countries, vehicles may not have crash protective devices, the lack of which can increase one's injuries during road crashes. ${ }^{7}$ Failure to have these safety devices can increase the severity of these crashes. ${ }^{8}$ The estimated cost of highway crashes to governments worldwide is estimated to be 518 billion US dollars. ${ }^{4}$

In Abu Dhabi, UAE, a total of 77 deaths from 1,395 traffic accidents were recorded in the first six months in 2017 compared to 112 deaths for the same period last year. In Dubai a $40 \%$ drop in rate of fatal traffic accidents was also recorded, and authorities attribute such reductions to various awareness campaigns and security steps. ${ }^{9}$ According to a recent research by the Roadway, Transportation and Traffic Safety Research Centre (RTTSRC), the UAE suffers about 10,000 crashes annually, resulting in 2.7 fatalities per day and road accidents and injuries are costing the economy Dh20 billion (about $\$ 5.5$ billion) annually. Police authorities are aiming at reducing the number of fatalities caused by road accidents to zero per 100,000 populations by $2020 .{ }^{10}$ Distraction of driving by using mobile phones to talk or text messages while driving and by eating, drinking, trying to control children and the ignorance of children safety measures in the car significantly contributes to traffic accidents. Moreover, high speed and irresponsible driving are not only hazardous to the driver and his/her passengers but also to other drivers and pedestrians.

Concern on the influence of illicit, prescription and overthe-counter (OTC) drugs on judgment of drivers is on the rise as the use of such drugs and medications may impair cognition, leads to drowsiness or a slow reaction time of drivers. In the present study, slightly more than half $(78$, $52 \%$ and $80,53.3 \%$ ) the responders were within 17-28 years of age and with a university degree respectively. Young age drivers are always at higher risk of traffic accidents than elder counter parts because they tend to enjoy speed driving and use mobile phones while driving. Negligence and lack of attention are main causes of fatalities in car accidents. It has been stressed that despite the strict law on seat belt usage in UAE, a significant percentage of the drivers do not wear a seat belt either while driving or when in someone else's car. ${ }^{11} \mathrm{We}$ also observed that some drivers admitted not to follow driving regulations and do not use seat built.

Use of medications as a cause of accidents was reported by only $4(2.7 \%)$ participants. Some prescription and overthe-counter (OTC) drugs have been proved to markedly impair cognition, cause drowsiness and influence 
judgment of drivers and slow reaction time of drivers. It has been documented in Dubai police statistics (3) that during 2007-2009, traffic accidents due to sleep counted for $0.07 \%$ ( 7 accidents out of 10560) while accidents due to sleep under the influence of specific drugs during 20082009 comprised only $0.03 \%$ (3 accidents out of 7225). ${ }^{12}$ On the other hand, Sharjah police statistics ${ }^{13}$ reported that during 2001-2007, a total of 14091 accidents were mainly due to driver's negligence. Accidents because of inability to concentrate due to specific medication counted for 1501 accidents, but no separate records of those due to medication use. ${ }^{13}$ In view of our finding that slightly less than $50 \%$ of drivers in this study either rarely or never read the instruction leaflets of their medications, it seems reasonable to suggest that problems encountered with use of prescription/ OTC may be reduced by both the prescribing physicians and the dispensing pharmacists instructing drivers on possible risks of driving while under the influence of certain medications. Both healthcare professionals can also advice drivers on the best time to take their drowsiness- or sleep-inducing medications. It must be stressed here that a drowsy driver does not only pose a hazard to ones' self but to other road users including other drivers, pedestrians and children. Therefore, it is important to note that when it comes to public safety, negligence and ignorance of safe road regulations even if it is practiced by a small or insignificant number of drivers should be alarming and should be taken seriously. The aim of the authorities in UAE is to reach the record zero traffic accidents. A target that drivers should help to achieve by following actively participating in campaigns and activities directed as increasing awareness of safe driving.

\section{CONCLUSION}

The results of this study support the development of educational program to increase awareness about the potential hazards of driving under the influence of prescription/OTC drugs. Also physician and pharmacist should provide patients with instructions and warning on medications that influence alertness. Authorities are advised to develop new regulations with respect to driving under the influence of medications or when suffering diseases that affect driving ability.

\section{ACKNOWLEDGEMENTS}

The authors would like to thank Dubai and Sharjah police for their invaluable advice and information. The authors thank all the drivers who willingly participated in the study.

Funding: No funding sources

Conflict of interest: None declared

Ethical approval: The study was approved by the Institutional Ethics Committee

\section{REFERENCES}

1. Gopalakrishnan S. A Public Health Perspective of Road Traffic Accidents. J Family Med Prim Care. 2012;1(2):144-50.

2. Goullé JP, Verstraete A, Boulu R, Costentin J, Foucher JP, Raes E, et al. Illicit drugs, medications and traffic accidents. Annales Pharmaceutiques Françaises. 2008;66(4) 196-205.

3. Peden M, Scurfield R, Sleet D, Mohan, D, Hyder AA, Jarawan E, et al., World report on road traffic injury prevention. Geneva: World Health Organization; 2004. Accessed 10 January 2018.

4. World Health Organization. Global Status Report on Road Safety: Time for Action. Geneva: World Health Organization; 2009. Accessed 15 January 2018.

5. Association for Safe International Road Travel. Available at: http://asirt.org/initiatives/informingroad-users/road-safety-facts/road-crash-statistics. Accessed 16 January 2018.

6. World Health Organization. Global Health Observatory (GHO) data, Road traffic deaths., Available at: http://www.who.int/gho/road_safety/mortality/en/. [Accessed 15 December 2017].

7. Al Junaibi, MM, Georgakis P, Mushatat S. Examining the direct effect of the use of traffic safety technologies in Abu Dhabi highways on other traffic safety dimensions. J. Traffic and Logistics Engineering, 2017;5(1):1-9.

8. National Technical University of Athens Best practice for cost-effective road safety infrastructure investments. Australasian College of Road Safety Conference; 2012. Available at: http://www.cedr.fr/home/fileadmin/user_upload/Publ ications $/ 200$

8/e_Road_Safety_Investments_Report.pdf [Accessed 12 December 2017].

9. Al Kuttab J. UAE road accidents claim 315 lives so far this year. Khaleej Times; 2017. Available at: https://www.khaleejtimes.com/nation/dubai/uae[Accessed 10 December 2017].

10. Gulf News. Road crashes and injuries cost UAE Dh20b yearly; 2018. Available at: http://gulfnews.com/news/uae/transport/road-crashesand-injuries- [Accessed 15 January 2018].

11. Hammoudi A, Karani G, Littlewood J. Road traffic accidents among drivers in Abu Dhabi, United Arab Emirates. J. Traffic and Logistics Engineering. 2014;2(1):7-12.

12. Dubai police statistics. Available at: www.dubaipolice.gov.ae. [Accessed 10 December 2017].

13. Sharjah police. Available at: www.sharjahpolice.gov.ae. [Accessed 10 December 2017].

Cite this article as: Sharif SI, Sharawy MA, Makrem D, Qasim E, Shemi D. Traffic accidents and medicine use in United Arab Emirates. Int J Basic Clin Pharmacol 2018;7:660-4. 